\title{
Techno-economic feasibility of a pre- oxidation process to enhance prereduction of chromite
}

\author{
by E.L.J. Kleynhans* ${ }^{\dagger}$, J.P. Beukes*, P.G. van Zyl*and \\ J.I.J. Fick ${ }^{\dagger}$
}

\section{Synopsis}

Ferrochrome ( $\mathrm{FeCr}$ ) is vital for the production of stainless and high-alloy ferritic steels, since it is the only source of new $\mathrm{Cr}$ units. $\mathrm{FeCr}$ production is an energy-intensive process. The pelletized chromite prereduction process is most likely the FeCr production process with the lowest specific electricity consumption (SEC), i.e. $\mathrm{MWh} / \mathrm{t}$, currently in operation. However, due to increases in costs, efficiency, and environmental pressures, FeCr producers are attempting to lower their overall energy consumption even further. Recently, it was proven that pre-oxidation of chromite ore prior to pelletization and prereduction significantly decreases both the SEC and lumpy carbonaceous reductants required for smelting. This paper presents the first attempt at conceptualizing the technoeconomic feasibility of integrating chromite pre-oxidation into the prereduction process. Financial modelling yielded a net present value (NPV) at a $10 \%$ discount rate of approximately R900 million and an internal rate of return (IRR) of approximatelyy $30.5 \%$ after tax, suggesting that the implementation of pre-oxidation prior to pellet prereduction may be financially viable. Sensitivity analysis indicated that the parameter with the greatest influence on project NPV and IRR is the level of prereduction. This indicates that the relationship between maintaining the optimum pre-oxidation temperature and the degree of prereduction is critical for maximium process efficiency.

Keywords

chromite prereduction, solid-state reduction, pre-oxidation, discounted cash flow model, techno-economic feasibility.

\section{Introduction}

Stainless steel is a crucial alloy in modern society. Virgin chromium $(\mathrm{Cr})$ units used in the manufacturing of stainless steel are obtained from ferrochrome $(\mathrm{FeCr})$ - a relatively crude alloy consisting predominantly of $\mathrm{Cr}$ and iron (Fe) (Murthy, Tripathy, and Kumar, 2011; Beukes, van Zyl, and Ras, 2012). FeCr is produced mainly by the carbothermic reduction of chromite ore in submerged arc furnaces (SAFs) and direct current arc furnaces (DCFs) (Neizel et al., 2013; Beukes, Dawson, and van Zyl, 2010; Dwarapudi et al., 2013). The energy required to heat, smelt, and reduce the chromite ore to the metallized state is supplied by electricity (Pan, 2013). FeCr production is an energy-intensive process, with a specific electricity consumption (SEC) varying from 2.4 $\mathrm{MWh} / \mathrm{t}$ to more than $4.0 \mathrm{MWh} / \mathrm{t} \mathrm{FeCr}$ produced, depending on the process applied (Pan, 2013; Neizel et al., 2013). Daavittila, Honkaniemi, and Jokinen (2004) stated that the typical operational costs of $\mathrm{FeCr}$ smelters can be divided into four categories, i.e. chromite ore $(30 \%)$, carbonaceous reductant $(20 \%)$, electricity $(30 \%)$, and other production costs (20\%). This makes electricity consumption the joint largest factor that influences operational costs in $\mathrm{FeCr}$ production.

Beukes, Dawson, and van Zyl (2010) presented an overview of processes utilized for $\mathrm{FeCr}$ production, with specific reference to the South African FeCr industry. However, similar processes are also applied internationally. According to this review, $\mathrm{FeCr}$ is produced in:

(i) Conventional semi-closed/open submerged arc furnace (SAF) operations with bag filter off-gas treatment

(ii) Closed SAF operations that usually utilize oxidized, sintered pelletized feed, with venturi scrubbing of offgas

(iii) Closed SAF operations consuming prereduced pelletized feed, with venturi scrubbing of off-gas

(iv) Closed direct current (DC) arc furnace operations, with venturi scrubbing of off-gas.

Until now, these processing options have allowed for economical FeCr production, particularly in countries with local chromite resources (Daavittila, Honkaniemi, and Jokinen, 2004). Although equipment has been improved and modern automation systems implemented, there are still some significant areas in which the technology can be improved further:

* Chemical Resource Beneficiation, North-West University, Potchefstroom Campus,

Potchefstroom, South Africa.

+ Centre for Research and Continued Engineering Development - CRCED Vaal, Faculty of Engineering, Vaal Triangle Campus, North-West University, Vanderbijlpark, South Africa.

(C) The Southern African Institute of Mining and Metallurgy, 2017. ISSN 2225-6253. Paper received Nov. 2015; revised paper received May. 2016. 


\section{Techno-economic feasibility of a pre-oxidation process to enhance prereduction}

(i) The efficient use of energy (electricity and chemical energy in the form of reductants) and the utilization of secondary energy produced (e.g. CO-rich off-gas, radiation heat)

(ii) Increased use of lower cost raw materials through advanced beneficiation and agglomeration, or corresponding technologies

(iii) Larger production units in order to benefit from economies of scale

(iv) Increased automation to improve operation (Daavittila, Honkaniemi, and Jokinen, 2004).

These factors, coupled with the fact that SAF and DC smelting operations can be regarded as having reached the 'mature' phase of development, indicate that FeCr producers and their main customers, the stainless steel producers, should consider more cost- and quality-effective production of Cr units (Slatter, 1995; Holappa, 2010). FeCr producers face significant challenges, including a downward trend in FeCr prices, increasing awareness of environmental impacts and working conditions, increasing electricity costs (and availability in some countries), and carbon footprint reduction requirements (Daavittila, Honkaniemi, and Jokinen, 2004) that will require innovative advances in process technologies (Ugwuegbu, 2012).

Various measures to improve FeCr production by the SAF process have been investigated (Kapure et al., 2010; Daavittila, Honkaniemi, and Jokinen, 2004; Slatter, 1995; Goel, 1997; Ugwuegbu, 2012). These measures mainly involved prereduction and preheating methods in order to improve $\mathrm{Cr}$ recoveries and minimize smelting costs. The pelletized chromite prereduction process (commercially known as the Premus process), applied by two Glencore Alloys FeCr smelters in South Africa, comprising six large smelting SAFs, is considered to be the FeCr production process option with the lowest SEC currently in operation (Kleynhans et al., 2012). Similar smelters are being commissioned in China, but no information regarding these operations is currently available in the peer-reviewed public domain. The SEC of the pelletized chromite prereduction process is approximately $20 \%$ lower than that of its nearest rival, the SAF smelting process with oxidized sintered pellets as furnace feed (commercially referred to as the Outotec technology) (Neizel et al., 2013). The pelletized chromite prereduction process also has some disadvantages, as indicated by Mohale (2014), i.e. the higher capital cost and the extensive operational control required due to the variation in prereduction level and carbon content of the prereduced pelletized furnace feed material.

In view of the previously mentioned challenges faced by FeCr producers, and regardless of the lower SEC of the pelletized chromite prereduction process, it is apparent that smelters applying this process would benefit from a process improvement capable of achieving even lower SEC. Beukes, van Zyl, and Neizel (2015) developed a new process in which chromite ore is oxidized before prereduction. This patented process was reviewed by Kleynhans et al. (2015). They found that pre-oxidation enhanced the susceptibility of the chrome spinel to prereduction, mainly by Fe liberation and preventing the release of chromium (III) oxide $\left(\mathrm{Cr}_{2} \mathrm{O}_{3}\right)$ from the spinel (Beukes, van Zyl, and Neizel, 2015; Kleynhans et al., 2015). As indicated by Niayesh and Fletcher (1986), an increase in the level of prereduction will result in a decrease in SEC. Beukes, van Zyl, and Neizel (2015) and Kleynhans et al. (2015) claimed that a reduction in SEC of approximately $8.5 \%$ can be achieved.

This investigation was carried out to assess the economic feasibility of the pre-oxidation process applied as a pretreatment step in the pelletized chromite prereduction process, and to evaluate the effect on the economics of a typical FeCr smelter. This was done by analysing the cost efficiency of various cost model parameter options, as well as their subsequent development within a comprehensive cost model and discounted cash flow (DCF) model.

\section{Background to the feasibility study}

South Africa hosts the majority of global chromite reserves (Beukes, van Zyl, and Ras, 2012; Merafe Resources, 2012; Creamer, 2013). The majority of South Africa's chromite ore is relatively friable. It is therefore common to recover only $10-15 \%$ lumpy ore $(15-150 \mathrm{~mm})$ and $8-12 \%$ chip/pebble ore $(6-15 \mathrm{~mm})$ during the beneficiation process. The remaining ore would typically be in the $<6 \mathrm{~mm}$ fraction, and would usually be crushed and/or milled to $<1 \mathrm{~mm}$ and then upgraded utilizing gravity separation techniques (e.g. spiral concentrators) to approximately $45 \% \mathrm{Cr}_{2} \mathrm{O}_{3}$ content. This upgraded $<1 \mathrm{~mm}$ ore is commonly known as metallurgical grade chromite (Glastonbury et al., 2010). Upgraded chromite tailings $(<1 \mathrm{~mm})$ from platinum group metals (PGMs) concentrators treating the UGS Reef are also utilized as feed material for the South African FeCr industry (Cramer, Basson, and Nelson, 2004).

Effective SAF smelting operation requires a permeable burden to ensure the uniform flow of reduction gases and smooth furnace operation (Dwarapudi et al., 2013). The use of fine chromite ore in SAFs is limited, since fine materials increase the tendency of the surface layer of the SAF burden to sinter. This traps evolving process gas, which can result in so-called bed turnovers or blowing of the furnace, which can result in damage to equipment or injury to personnel. A process that can accommodate fine ore is therefore required. Typically an agglomeration step (e.g. pelletization) is employed prior to feeding into the SAF (Kleynhans et al., 2012; Beukes, Dawson, and van Zyl, 2010).

There are currently 14 individual FeCr production facilities in South Africa, with a combined capacity in the region of 5.2 Mt/a (Beukes, van Zyl, and Ras, 2012; Jones, 2015). The abundant chromite resources and comparatively low historical cost of electricity enabled South Africa to maintain its dominant position in the international $\mathrm{FeCr}$ industry, contributing on average $44.5 \%$ to global $\mathrm{FeCr}$ production in the period 2000 to 2011. However, in 2012, South Africa produced only $32 \%$ of the world's output, as production decreased by $30 \%$ from 2007 , with China becoming the largest FeCr producer (ICDA, 2013b). A number of factors led to this major downturn. Firstly, South Africa is facing several internal challenges that have adversely affected the manufacturing ability and production costs of $\mathrm{FeCr}$ producers. Historically, the country benefited from favourable, inexpensive logistics and relatively cheap labour. This is no longer the case, due to the country's energy and labour problems. By the end of 2007, the electricity demand in South Africa caught up with the generating capacity. In 


\section{Techno-economic feasibility of a pre-oxidation process to enhance prereduction}

order to avoid destabilization of the national electricity grid, rolling blackouts were implemented. Erosion of surplus generation capacity led to a dramatic increase in the nominal price of electricity; by about $245 \%$ between 2007 and 2013 (Eskom, 2012).

In 2012, Eskom, the country's state-controlled energy supplier, realized that it would not be able to support total electricity demand, and agreed to reimburse FeCr smelters that did not use already-contracted electricity supply and temporarily shut down their furnaces. This lack of energygeneration capacity is the result of years of underinvestment in the electricity sector. FeCr smelters, facing low prices for their product, welcomed the proposition and started to shut down their furnaces. Anecdotal evidence indicated that it was more profitable for them to sell energy back to Eskom than to produce FeCr. Eskom announced in early 2013 that it needed R50 billion (approximately US $\$ 5$ billion) more than planned to meet funding needs in the five years until 2018. This was in addition to the R225 billion shortfall in revenue due to higher coal prices and increased capex expenses. Eskom needed to invest immensely in new capacity, but the National Electricity Regulator of South Africa (NERSA) refused the price increase of 16\% per year requested by Eskom for 2013 to 2018. Instead, NERSA granted Eskom permission to raise the energy tariff by $8 \%$ per annum for the following five years, to finance investments in new generation capacity. Furthermore, Eskom struggles to source the coal it requires. Coal production has to rise from the current $254 \mathrm{Mt} / \mathrm{a}$ to more than $320 \mathrm{Mt} / \mathrm{a}$ by 2020 to satisfy demand. In addition China, South Africa main FeCr customer, has increased domestic FeCr production and reduced imports, taking advantage of the increasing demand for $\mathrm{FeCr}$ and filling the gap in the market. Lower shipping costs, brought about by the slowdown in the world economy, made geographical positioning of smelters less relevant. Therefore, at present, South Africa ships less FeCr to China, which now imports more chromite ore from South Africa and smelts it locally to supply its stainless steel industries (ICDA, 2013a, 2013b).

Against this background, the South African FeCr industry is ideal for this feasibility study. South Africa holds the majority of the world's chromite resources, the ore is friable which necessitates an agglomeration process step, and the energy situation justifies exploring new FeCr production technologies to reduce SEC.

\section{Process options}

Although the pre-oxidation process prior to prereduction has been patented (Beukes, van Zyl, and Neizel, 2015), it has not yet been applied on an industrial scale. The process therefore needs to be matched with appropriate equipment. Equipment used in currently applied and previously attempted pretreatment options could be considered to serve for this purpose.

Outotec's steel belt sintering process is the only commercially applied FeCr process that utilizes oxidation as a pretreatment method prior to smelting in the SAF. The preoxidation of unagglomerated chromite ore prior to prereduction (solid-state reduction of chromite) must not be confused with oxidation prior to smelting. Furthermore, reduction during smelting in an SAF, when the ore is completely reduced to the zero oxidation or metallic state, must not be confused with prereduction, where the ore is only partially reduced. Molten or liquid materials are formed during the smelting reduction process, but not during prereduction, hence the alternative terminology 'solid-state reduction'. The primary raw materials in the Outotec steel belt sintering process, which has been the most commonly applied process over the last decade in the South African FeCr industry, are ore fines, a refined clay binder, and fine coke. The ore and coke are wet-milled in a ball mill to approximately $90 \%$ smaller $\left(d_{90}\right)$ than $108 \mu \mathrm{m}$ (Glastonbury et al., 2015) and dewatered in capillary-type ceramic filters. The dewatered material is mixed with a clay binder and pelletized in a drum pelletizer before finally being sintered in the steel belt sintering furnace. The fixed carbon $(\mathrm{FC}$ ) content (from coke fines) added in the steel belt sintering feed mixture is low $(1-2 \%)$ compared to the FC content of the feed mixture for prereduction (12.5-15\%). The sintering process is basically an oxidative process, during which the carbon in the pellets is oxidized to sinter the pellets (Beukes, van Zyl, and Ras, 2010; Glastonbury et al., 2015).

In rotary hearth furnace technology, normally applied as a preliminary heating or reduction step prior to smelting, ore, reductants, and fluxes are milled to typically less than 100 $\mu \mathrm{m}$ before being blended, mixed, and fed into a pelletizing plant. The green pellets are dried using exhaust gas from the rotary hearth furnace. The furnace operates continuously and the pellets are sintered, reduced, and cooled in controlled zones with a maximum zone temperature of $1450^{\circ} \mathrm{C}$ (Slatter, 1995). The reduction occurs in stages in different zones of the furnace. Additional hot air is introduced into the rotary hearth furnace to control the temperature and the composition of the atmosphere in order to provide conditions conducive to the optimal reduction of chromite and minimize re-oxidation. Once the material has passed through the rotary hearth furnace, it is discharged and can be cooled using various methods. Energy for the sintering and prereduction zones can be provided by the oxidation of the $\mathrm{CO}$ gas obtained from the exhaust gas of SAFs (Slatter, 1995). The rotary hearth furnace, if operated with an oxidizing atmosphere, could be applied for pre-oxidation.

Fluidized beds are ideally suited for the processing of finely sized raw materials (Luckos, Denton, and den Hoed, 2007). Since the fluidized bed can be used as a preheater for chromite, it can also be considered as a means to pre-oxidize ore prior to prereduction. Laboratory-scale preheating tests with chromite ores and coals were carried out in a fluidized bed facility at Lurgi Metallurgie, followed by a pilot-scale test in a four-stage flash preheater at Polysius AG. These tests confirmed that chromite ores and fluxes can be thermally treated up to a gas temperature of $1150^{\circ} \mathrm{C}$ without succumbing to the forces of attrition and producing fines, or forming low-melting-point phases and agglomerating. Denton, Bennie, and de Jong (2004) stated that the best option from an economic point of view is to use CO-rich furnace off-gas to preheat the chromite and fluxes to $1200^{\circ} \mathrm{C}$.

The rotary kiln serves as the process unit for a number of preheating and prereduction process technologies. In principle, rotary kilns can be effectively used for preheating charge by making use of CO-rich furnace off-gas. The use of a rotary kiln for prereduction of chromite ore was developed and applied on an industrial scale by three companies Outokumpu, Showa Denko, and Krupp/MS\&A (McCullough 


\section{Techno-economic feasibility of a pre-oxidation process to enhance prereduction}

et al., 2010; Ugwuegbu, 2012). Outokumpu used a rotary kiln for preheating pellets to $1000^{\circ} \mathrm{C}$ before continuously feeding the preheated pellets to a closed SAF. Outokumpu studied its process for approximately ten years on the laboratory and pilot scale, as well as for two years in a commercial-scale operation utilizing a rotary kiln with a length of $55 \mathrm{~m}$ and an inner diameter of $2.3 \mathrm{~m}$ (Daavittila, Honkaniemi, and Jokinen, 2004). The process involved grinding and pelletizing of ore fines, followed by sintering of green pellets that were prereduced before smelting. The ore and coke fines used by Outokumpu were wet-ground to approximately $d_{35} 37 \mu \mathrm{m}$ and then pelletized to approximately $15 \mathrm{~mm}$ diameter. The bulk of the fuel for sintering and prereduction of the pellets was provided by CO-rich off-gas from closed SAFs (Goel, 1997). Showa Denko's process for prereducetion of pellets is still in use. It was installed by Consolidated Metallurgical Industries in South Africa in the mid-1970s. This was the first commercial prereduction process for chromite. In this process, chromite ore fines are milled to $d_{90}<75 \mu \mathrm{m}$, pelletized with coke as reductant, and fired in a rotary kiln to approximately $1400^{\circ} \mathrm{C}$. The kiln is heated by a pulverized coal burner. The pellets, with approximately 40-60\% metallization of $\mathrm{Cr}$ and $\mathrm{Fe}$, are discharged into an SAF for final smelting (Naiker, 2007; Naiker and Riley, 2006).

To address some of the apparent weaknesses of the Showa Denko K.K. (SDK) process, Krupp commenced development of a rotary kiln prereduction process in 1984, based upon their CODIR process. In this process, chromite ore and coal fines react in a rotary kiln at temperatures approaching $1450^{\circ} \mathrm{C}$ to produce a semi-solid product consisting of highly metallized $\mathrm{FeCr}$, slag, gangue, and char. A high temperature and intimate contact between the chromite grains and carbon are necessary over the entire residence time in the kiln in order to achieve a high degree of metallization $(>90 \%)$. For this purpose, the burden is transformed into a semi-solid state with a combination of molten and solid phases, to allow for only a small portion of the surface of the metallized phase to be exposed to air without macroscopic phase separation occurring (McCullough et al., 2010).

The Premus process, currently applied by Glencore Alloys, was developed from the SDK/CMI process. In this process, anthracite or char is used as a reductant instead of coke. Similar to the SDK/CMI process, the raw materials are drymilled, pelletized, preheated, and fed into a rotary kiln. Pure oxygen and a pulverized carbon fuel (PF) are used to fire the kiln (Basson, Curr, and Gericke, 2007; Naiker, 2007; Naiker and Riley, 2006; Ugwuegbu, 2012). Kleynhans et al. (2012) indicated that while the pellets are exposed to the high temperatures inside the rotary kiln, the carbon in the outer layer of the pellets is mostly burned off and a partially oxidized outer layer is formed. A small amount of $\mathrm{Fe}$ reduction can occur before all the carbon is consumed in this outer layer, and this Fe can be re-oxidized. Oxygen ingress to the core does not take place, since $\mathrm{CO}$ gas formed from the carbon inside the pellets produces a positive partial pressure. This positive $\mathrm{CO}$ pressure is therefore necessary to prevent re-oxidation of the pellets. If chromite ore is fed into the kiln without a carbon reductant to generate $\mathrm{CO}$, natural oxidation would consequently occur as required for the pre-oxidation process.
The disadvantage of the Outotec steel belt sintering process is that the raw materials used, including the ore, are milled and pelletized before being sintered in an oxidizing environment. These pellets would have to be pulverized in order to use them in the prereduction process. The energy and raw materials used to initially pelletize the ore for preoxidation would therefore be wasted. The rotary hearth furnace and fluidized-bed processes offer an interesting alternative, but although they have been tested on a pilot scale, these processes have not yet progressed to successful large-scale operation in the $\mathrm{FeCr}$ industry and further development is required. Of the four abovementioned options, the one most likely to be implemented by FeCr producers already utilizing the prereduction process is the rotary kiln. FeCr producers using chromite prereduction are accustomed to kiln operation and would prefer this route as it fits within their current prereduction operations culture. It also has an advantage from a maintenance perspective, i.e. employing a kiln with the same diameter for pre-oxidation as the kiln used for prereduction. This standardization of equipment components would reduce spare parts requirements, thereby lowering capital that is tied up.

\section{Process descriptions}

Since it is expected that a countercurrent rotary kiln will be used if the pre-oxidation process is implemented at a smelter already applying the pelletized chromite prereduction process (see discussion in the preceding section), a hypothetical process flow diagram was developed consisting of a rotary kiln and axillary equipment. This flow diagram, together with the flow diagram of the current industrially applied prereduction process, is presented in Figure 1. In the chromite pre-oxidation process (Figure 1A), fine chromite ore in the holding silos is fed via weight feeders onto a conveyer that feeds the kiln. Inside the kiln, the ore is oxidized by the thermal energy supplied by pulverized coal and/or furnace off-gas at the discharge end of the kiln. A gas fan at the feed end pulls air through the kiln. The air leaving the kiln is sent to a cyclone to remove coarse particles $(<1 \mathrm{~mm})$, and then to a baghouse for removal of finer particles $(<30 \mu \mathrm{m})$ before being released to the atmosphere (Pšunder, 2012). The preoxidized fine chromite ore $(\mathrm{OC})$ is then discharged into a bunker and transported to the prereduction raw material storage heaps. The oxidizing temperature inside the kiln is controlled by measuring the ore discharge temperature with an optical sensor. The pre-oxidized fine chromite ore is then fed as raw material into the prereduction process (Figure 1B), instead of normal chromite ore. The prereduction and smelting process flow (Figure 1B) is not discussed here, since detailed discussions are available elsewhere (Ugwuegbu, 2012; Naiker, 2007; Naiker and Riley, 2006; Botha, 2003). The off-gas produced during SAF smelting is cleaned through a venturi water-scrubbing system and recycled, specifically to the chromite pre-oxidation process, to serve as an energy source.

\section{Methodology \\ Quantification of process benefits associated with chromite pre-oxidation}

From experimental results presented by Kleynhans et al. 


\section{Techno-economic feasibility of a pre-oxidation process to enhance prereduction}

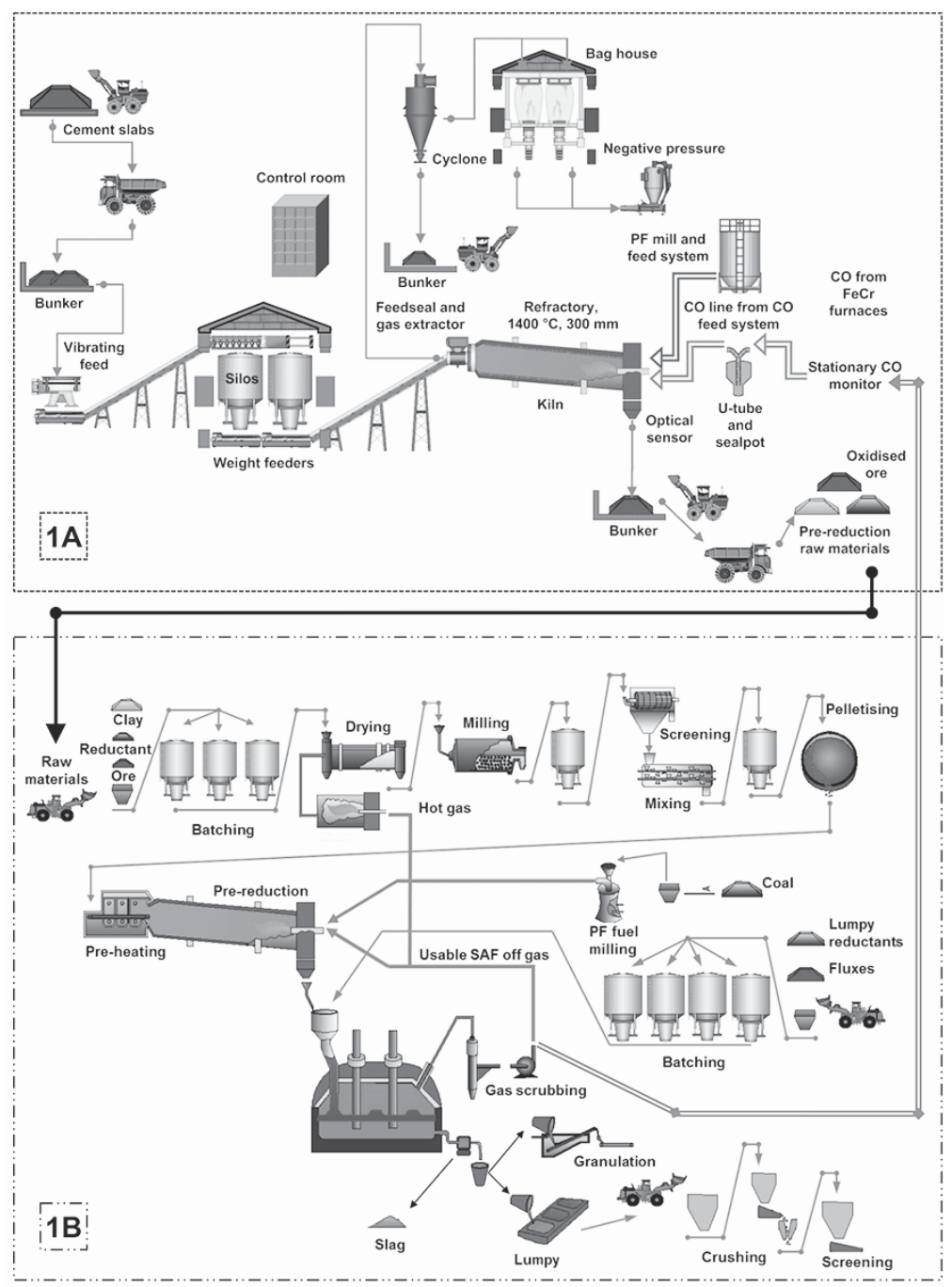

Figure 1-(A) Pre-oxidation process, (B) prereduction process

(2015), it is evident that the level of prereduction could be considerably enhanced through the pre-oxidation of chromite ore prior to prereduction. The advantages of improved prereduction can be observed in several aspects of the operation. However, the main advantages include the decrease in SEC and lumpy carbonaceous reductants required for SAF operation. Niayesh and Fletcher (1986) published a graph of chromite prereduction as a function of SEC, for different temperatures of prereduced feed material. Kleynhans et al. (2015) reconstructed and empirically fitted the data from Niayesh and Fletcher (1986) to estimate the improvement in SEC. They also used the fundamental carbon-based metallization and reduction reactions for chromite presented by Barnes, Finn, and Algie (1983) to calculate the decrease in FC content associated with the lumpy reductants fed into the SAF. The improvements in both the aforementioned parameters, i.e. SEC and FC requirement, due to pre-oxidation are illustrated in Figure 2, utilizing the assumption that pre-oxidation of the chromite takes place at $1000^{\circ} \mathrm{C}$,

From Figure 2 it is evident that with an increase in prereduction, less FC is required for smelting. Although one could directly calculate the electrical energy financial gain from the improved SEC, annual FeCr production capacity, and

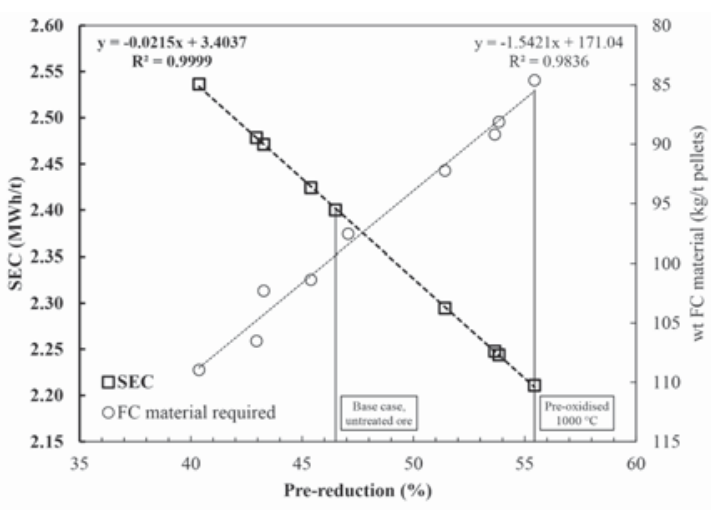

Figure 2-The effect of enhanced prereduction by utilizing pre-oxidized fine chromite ore (x-axis) on the SEC (primary $y$-axis), as well as on the FC required per ton of prereduced pellets ( (secondary $y$-axis) (Kleynhans et al., 2015)

the current price of electricity, this would not be a true reflection of the financial advantage. An electric arc furnace is designed according to a specific apparent power (S). However, only a fraction of this power, called the power factor $\left(K_{p}\right)$, is available as electrical energy for smelting. This 


\section{Techno-economic feasibility of a pre-oxidation process to enhance prereduction}

total available electrical energy, called the active power $(P)$, is a constant and cannot be changed. The production capacity of an operation is determined by dividing the active power by the SEC. Therefore, since the total energy available cannot be changed, the benefit of improved or lower SEC is realized as an increase in the production capacity. This implies that, as a result of an increase in prereduction levels, for the same total available electrical energy, FeCr production is increased.

\section{Cost distribution}

The typical cost factors for the FeCr industry in European conditions were presented by Daavittila, Honkaniemi, and Jokinen (2004). According to Biermann, Cromarty, and Dawson (2012), the cost factors for South African FeCr smelters vary to some extent, with chromite ore, reductants, and electricity each accounting for $30 \%$ of the production costs while factors such as maintenance, labour, and waste disposal account for the remaining 10\%. An analysis of South African FeCr input costs conducted by Cartman (2008) differed from that of Biermann, Cromarty, and Dawson (2012), with chromite ore accounting for 38\%, electricity for $18 \%$, reductants and other raw materials for $24 \%$, and maintenance, overheads, and labour for $20 \%$. The difficulty in interpreting these cost distributions is that in none of these references mentioned the process(es) to which the cost distribution was linked. They could therefore refer to any of the process combinations mentioned in the 'Introduction' section (Beukes, Dawson, and van Zyl, 2010), and the cost distributions for different process combinations will certainly vary. In order to conduct the financial modelling, it was important to consider life-cycle costs associated with the implementation of the chromite pre-oxidation process and the cost distribution of the chromite prereduction smelting operation. Since previously cited FeCr costs estimates (Daavittila, Honkaniemi, and Jokinen, 2004; Biermann, Cromarty, and Dawson, 2012; Cartman, 2008) did not focus specifically on the prereduction process, a life-cycle cost factor breakdown of the chromite pre-oxidation process in combination with the prereduction process was developed, as illustrated in Figure 3.

The life-cycle costs for both the chromite pre-oxidation process and prereduction process were divided into initial development costs (e.g. environmental impact assessment, design), capital costs, operating costs, and decommissioning costs, with the operating costs for both processes being subdivided into fixed and variable costs. As mentioned in the previous section, increasing the prereduction level decreases the reductant content required for smelting in the furnace, as well as increasing production capacity with the same total active power. Therefore, from a cost distribution perspective, both the electricity and reductant cost factors $(\mathrm{R} / \mathrm{t} \mathrm{FeCr})$ are lowered for the prereduction process, while production capacity is increased (refer to previous section). The net result is a decrease in other cost factors, e.g. maintenance, labour, waste disposal, and overheads, due to the dilution of fixed costs, and ultimately a decrease in the overall production cost (R/t FeCr).

\section{Discounted cash flow (DCF) analysis}

DCF analysis methods are capable of producing a good approximation of the value of a project in order to aid in the feasibility evaluation process. According to Hitch and Dipple (2012), it is fairly simple to appraise a project in terms of revenue versus cost; however, it is imperative to consider the time value of money and the influence that substantial upfront capital costs may have. Pšunder (2012) pointed out that the use of DCF methods for engineering project evaluation has increased significantly in the last few decades. Financial analysis through DCF modelling is currently the most commonly used methodology for appraising potential investments, due to its ability to quantify the added value to shareholders (Hitch and Dipple, 2012). Pšunder and Ferlan (2007) further indicated that net present value (NPV), net present value index (NPVI), internal rate of return (IRR), and modified internal rate of return (MIRR) are some of the most commonly used DCF methods, with NPV and IRR being the most frequently applied. The use of the IRR method is justifiable since it is easy to understand, due to the result being expressed as a percentage rate of return. Furthermore, results can easily be compared between various projects and different forms of investment. The regular use of the NPV method can be justified by the simplicity of the calculation (Pšunder, 2012).

\section{Assumptions}

As indicated in the 'Process options' section, it is likely that current $\mathrm{FeCr}$ producers utilizing the prereduction process would employ a rotary kiln for chromite pre-oxidation. The input parameters for the combined pre-oxidation and prereduction process (Figure 1) were obtained through

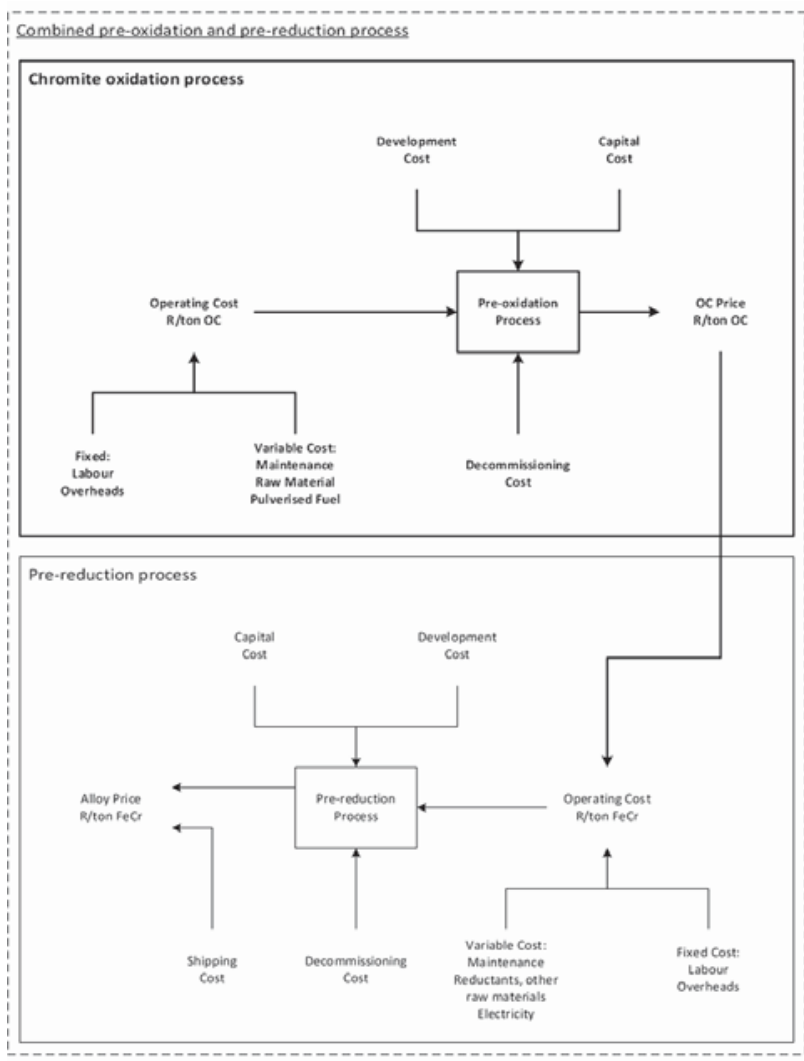

Figure 3-Life-cycle cost factor breakdown of the chromite preoxidation process, alone and in combination with the prereduction process 


\section{Techno-economic feasibility of a pre-oxidation process to enhance prereduction}

personal communications with individuals from a large South African FeCr producer that applies the pelletized chromite prereduction process and from personal experience in the FeCr industry. Capital costs were estimated by the general works project manager responsible for the first- and secondphase development of the largest single-phase $\mathrm{FeCr}$ expansion in the world, with both phases employing the prereduction process (Henrico, 2014). The base case input parameters used in this study, based on costs estimated in 2015, are presented in Tables I, II, and III. In the cost modelling, the chromite pre-oxidation (Figure 1A) and prereduction (Figure 1B) processes were kept as separate business units. Figure 4 presents a conceptual flow diagram of the financial model of the combined pre-oxidation and prereduction process (Figure 4A), indicating the effect of chromite pre-oxidation on SEC, lumpy carbonaceous reductant required for furnace smelting, and $\mathrm{FeCr}$ production (additional FeCr produced), compared to the prereduction process (Figure 4B). Revenue generated by the chromite preoxidation operation was divided into two income streams (Figure 4) - pre-oxidized chromite sales and $\mathrm{FeCr}$ production (increased revenue as a result of the increase in $\mathrm{FeCr}$ production capacity). The pre-oxidized chromite sale price is determined from the cost distribution of the prereduction process (Figure 4). The furnace reductant and electricity cost factors per ton $\mathrm{FeCr}$ are lowered by utilizing pre-oxidized chromite. A constant prereduction process production cost of R10 000 per ton FeCr was assumed, i.e. the same as before exploiting pre-oxidized ore. Therefore, the prereduction process chromite ore cost factor is increased, which sets the pre-oxidized chromite sale price. Using pre-oxidized chromite also results in an increased production capacity. The profit generated by the additional FeCr produced served as the second income stream for the chromite pre-oxidation process.

\section{Sensitivity analysis}

Although it is important to correctly approximate the operating and cost parameters of the combined pre-oxidation and prereduction process, these values will invariably change with economic circumstances and advances in research and development. Therefore, sensitivity analysis is essential in determining the overall feasibility pf the process. A more

Table I

Base case model input parameters (based on costs estimated in 2015)

\begin{tabular}{|c|c|c|}
\hline Input parameters & Value & Unit \\
\hline $\begin{array}{l}\text { Process availability } \\
\text { Available hours } \\
\text { Furnace capacity } \\
\text { Furnaces } \\
\text { Power factor } \\
\text { Total available electricity } \\
\text { Electricity price } \\
\text { R/US\$ exchange rate } \\
\text { Freight cost* (Wellmer et al., 2008) } \\
\text { FeCr price (Merafe Resources, 2014) } \\
\text { Cr content in FeCr produced } \\
\text { Coke price (Biermann et al., 2012) } \\
\text { Anthracite price (Biermann et al., 2012) } \\
\text { Char price (Biermann et al., 2012) } \\
{ }^{\star} \text { Shipping distance of approx. } 8300 \text { nmi } \\
\text { Furnace reductant mixture composition: }\end{array}$ & $\begin{array}{c}90 \\
7884 \\
63 \\
2 \\
0.879 \\
873600000 \\
0.74 \\
10.95 \\
25 \\
1.19 \\
50 \\
4000 \\
1100 \\
900\end{array}$ & $\begin{array}{c}\% / a \\
\mathrm{~h} \\
\mathrm{MVA} \\
- \\
- \\
\mathrm{kWh} / \mathrm{a} \\
\mathrm{R} / \mathrm{kWh} \\
\mathrm{R} / \mathrm{US} \$ \\
\mathrm{US} \$ \mathrm{t} \mathrm{FeCr} \\
\text { US\$/lb Cr contained } \\
\% \\
\mathrm{R} / \mathrm{t} \\
\mathrm{R} / \mathrm{t} \\
\mathrm{R} / \mathrm{t}\end{array}$ \\
\hline $\begin{array}{l}\text { Furnace reductant FC content } \\
\text { Coke } \\
\text { Anthracite } \\
\text { Char } \\
\text { Prereduction pellet composition: }\end{array}$ & $\begin{array}{c}77.8 \\
30 \\
20 \\
50\end{array}$ & $\begin{array}{c}w t \% \\
\% \\
\% \\
\%\end{array}$ \\
\hline $\begin{array}{l}\text { Chromite/OC } \\
\text { Reductant } \\
\text { Reductant FC content } \\
\text { Clay binder } \\
\text { Prereduction process (with unoxidized chromite): }\end{array}$ & $\begin{array}{l}76.5 \\
20.0 \\
75.0 \\
3.50\end{array}$ & $\begin{array}{l}\text { wt } \% \\
\text { wt } \% \\
\text { wt\% } \\
\text { wt\% }\end{array}$ \\
\hline $\begin{array}{l}\text { FeCr production capacity } \\
\text { Chromite consumption } \\
\text { Prereduction process pellet consumption } \\
\text { Prereduction level } \\
\text { Production cost } \\
\text { Combined pre-oxidation and pre-reduction process: }\end{array}$ & $\begin{array}{c}364000 \\
2.2 \\
2.876 \\
46.50 \\
10000.00\end{array}$ & $\begin{array}{c}\text { t FeCr/a } \\
\text { t chromite/t FeCr } \\
\text { t pellets/t FeCr } \\
\% \\
\mathrm{R} / \mathrm{t} \mathrm{FeCr}\end{array}$ \\
\hline $\begin{array}{l}\text { Prereduction increase } \\
\text { SEC } \\
\text { Kiln burner fuel composition } \\
\text { OC kiln PF consumption } \\
\text { FeCr production capacity } \\
\text { Chromite required } \\
\text { OC production } \\
\text { OC consumption } \\
\text { OC produced } \\
\text { OC prereduction pellet consumption } \\
\text { OC prereduction pellets required }\end{array}$ & $\begin{array}{c}8.50 \\
2220 \\
100 \\
0.0627 \\
393523 \\
865751 \\
1.014 \\
2.231 \\
877872 \\
2.916 \\
1147545\end{array}$ & $\begin{array}{c}\% \\
\text { kWh/t FeCr } \\
\% \text { PF } \\
\text { t PF/t OC } \\
\text { t FeCr/a } \\
\text { t chromite/a } \\
\text { t OC/t chromite } \\
\text { t OC/t FeCr } \\
\text { t OC/a } \\
\text { t OC pellets/t FeCr } \\
\text { t OC pellets/a }\end{array}$ \\
\hline
\end{tabular}




\section{Techno-economic feasibility of a pre-oxidation process to enhance prereduction}

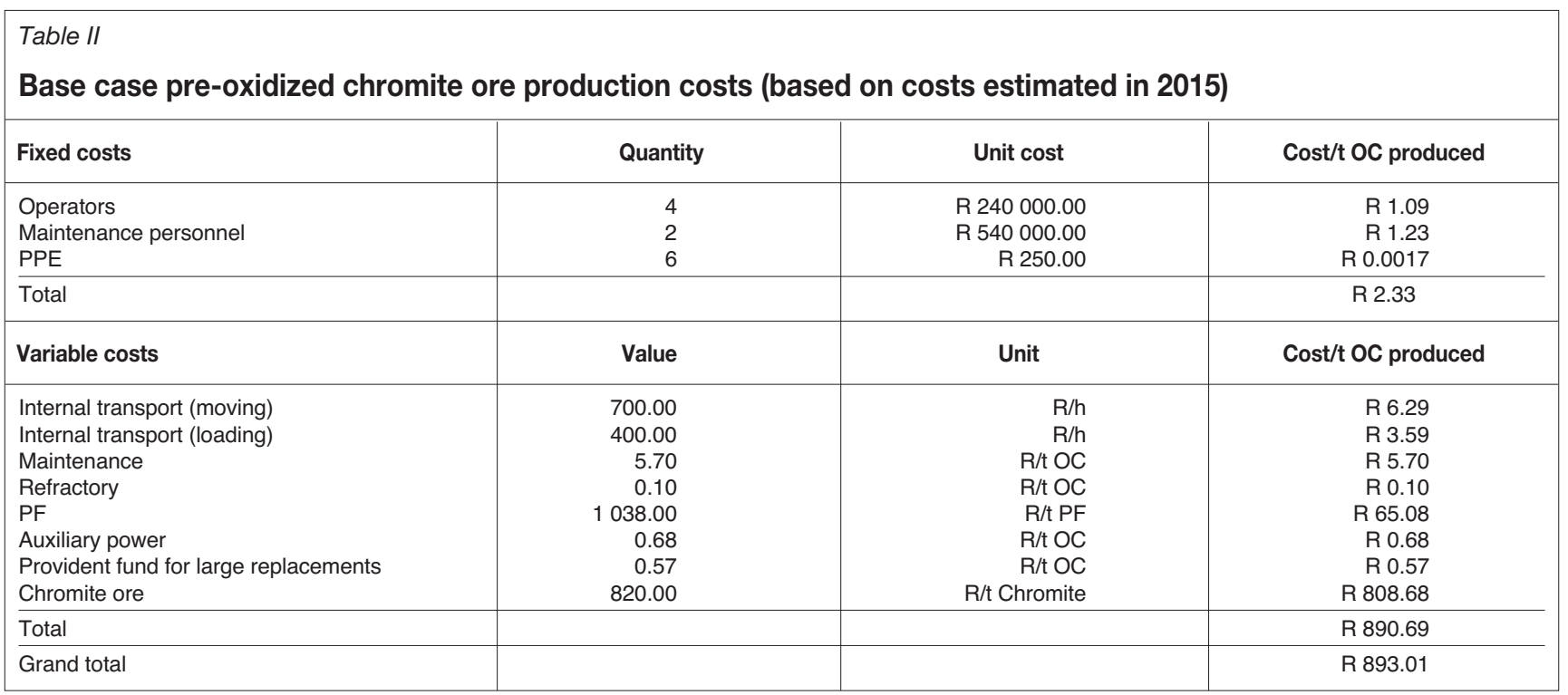

Table III

Base case DCF model input parameters (based on costs estimated in 2015)

\begin{tabular}{|c|c|c|}
\hline Input parameters & Value & Unit \\
\hline $\begin{array}{l}\text { Development phase duration } \\
\text { Development cost } \\
\text { Construction phase duration } \\
\text { Total capital cost: }\end{array}$ & $\begin{array}{r}1 \\
5 \\
2 \\
383627322\end{array}$ & $\begin{array}{c}\text { years } \\
\% \text { of total capital cost } \\
\text { years } \\
\text { R }\end{array}$ \\
\hline $\begin{array}{l}\text { Civils } \\
\text { Structural } \\
\text { Plate work } \\
\text { Mechanical } \\
\text { Electrical } \\
\text { Geotechnical studies } \\
\text { Project contingencies }\end{array}$ & $\begin{array}{r}71232000.00 \\
25446400.00 \\
14660800.00 \\
188182400.00 \\
32947376.00 \\
1120000.00 \\
15\end{array}$ & $\begin{array}{l}\mathrm{R} \\
\mathrm{R} \\
\mathrm{R} \\
\mathrm{R} \\
\mathrm{R} \\
\mathrm{R} \\
\% \text { of capital cost }\end{array}$ \\
\hline $\begin{array}{l}\text { Plant life } \\
\text { Depreciation } \\
\text { Decommissioning phase duration } \\
\text { Decommissioning cost } \\
\text { Cost escalation factor (inflation rate) } \\
\text { Benefit escalation factor (FeCr price increase) } \\
\text { Income tax rate } \\
\text { Discount rate }\end{array}$ & $\begin{array}{r}20 \\
5 \text { year MACRS } \\
2 \\
15 \\
6 \\
6 \\
28 \\
10\end{array}$ & $\begin{array}{c}\text { years } \\
\text { years } \\
\% \text { of total capital cost } \\
\% \\
\% \\
\% \\
\%\end{array}$ \\
\hline
\end{tabular}

comprehensive understanding of the project economics and viability can be achieved only by evaluating the ranges between extreme levels for the various input parameters. Similar to Hitch and Dipple (2012), sensitivity analysis was first performed on the input parameters for the pre-oxidation process production cost model, since the pre-oxidation process production cost is subsequently required as input to the DCF analysis. This allowed for the examination of deviations from the base case to assess the impact of the various input parameters. The sensitivity of each of these input parameters allowed for a more accurate appraisal of project value and return, as determined through DCF modelling and the corresponding sensitivity analysis.

\section{Financial modelling results and discussion}

Base case results

The base case results, consisting of the pre-oxidized chromite cost margins, the cost distributions of the prereduction process with and without pre-oxidized chromite, and the DCF model outputs, are listed in Table IV. In order to keep the production cost of the prereduction process constant at R10 000 per ton $\mathrm{FeCr}$, as explained in the 'Assumptions' section, the pre-oxidized chromite sales price was determined at R905.28 per ton OC. By employing the pre-oxidation process and utilizing pre-oxidized chromite the cost distributions of furnace electricity and reductants were reduced from $17.76 \%$ and $6.87 \%$ to $16.43 \%$ and $6.04 \%$, respectively. By applying the method used by Kleynhans et al. (2012) to convert improvements in electrical energy utilization to financial gains, the reduction in the furnace electricity cost distribution translated to approximately R48.5 million per annum for a 364000 t/a prereduction process. The financial gain associated with the decrease of the furnace reductant cost distribution (Figure 2) translates to approximately R30 million per annum for the $364000 \mathrm{t} / \mathrm{a}$ prereduction process. 


\section{Techno-economic feasibility of a pre-oxidation process to enhance prereduction}

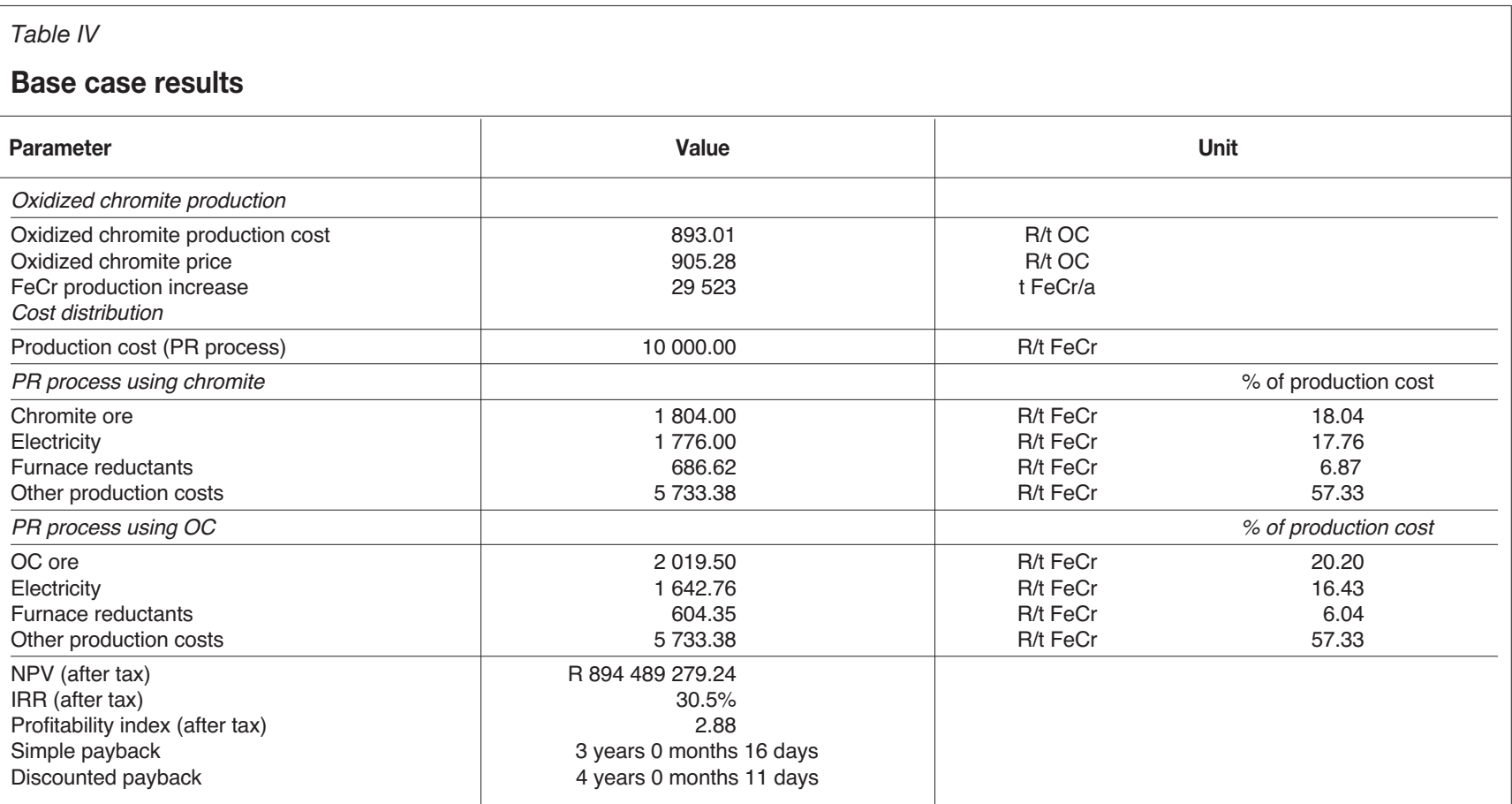

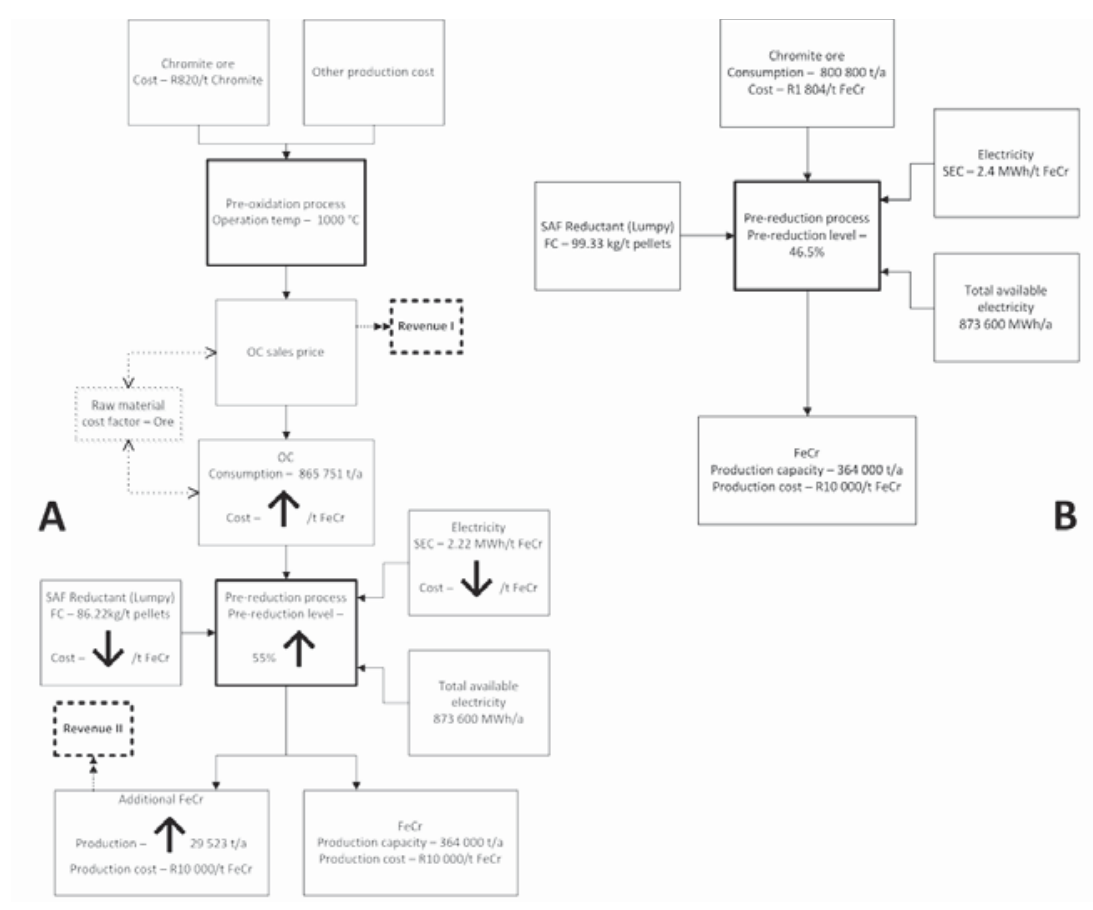

Figure 4-Conceptual flow diagram of the financial model for the combined pre-oxidation and prereduction process (A), indicating the influence of chromite pre-oxidation on SEC, lumpy carbonaceous reductant requirement for furnace smelting, and FeCr production (additional FeCr produced), the determination of the OC sales price, and the pre-oxidation process revenue streams (I and II), compared to the prereduction process (B)

It is therefore evident that applying this process has financial advantages.

Although not investigated in this study, another cost benefit resulting from employing the pre-oxidation process is the dilution of fixed costs. The large increase in production capacity effectively ensures a reduced impact of fixed cost, with the fixed cost increasing only slightly. For a preoxidized chromite production cost of R893.01 per ton OC and a FeCr production increase of $29523 \mathrm{t} / \mathrm{a}$, the DCF model yielded an NPV of approximately R895 million with an IRR of
$30.5 \%$ and a profitability index (PI) of 2.88 after tax. This significantly positive base case NPV, with the IRR approximately three times greater than the $10 \%$ discount rate and PI approximately three times higher than unity, suggests that integrating the pre-oxidation process and utilizing preoxidized ore may be a potentially feasible development option from a project economics standpoint.

In order to put these results into perspective, it would be beneficial to compare the NPV and IRR to other reasonable values within the industry. However, economic feasibility 


\section{Techno-economic feasibility of a pre-oxidation process to enhance prereduction}

results of smaller expansion or process improvement projects are not readily available in the peer-reviewed scientific domain, since the publication of such results could potentially erode the strategic advantage of the developing company. Development of the Ring of Fire, a large mineral resource-rich area of approximately $5120 \mathrm{~km}^{2}$ located in Canada's Northern Ontario region, can be considered as a recent example. Based on current projections, the chromite deposit is significant enough to sustain North American activity for a century (OCC, 2014). KWG Resources of Montreal, Canada released the preliminary economic assessment (PEA) study for the Big Daddy chromite deposit in the Ring of Fire in 2011. The PEA examined an open-pit mine, crushing plant, site infrastructure as well as development of a railway and power line to the site. Pre-production capital expenses were estimated to be around US\$784 million, which included half of the $\$ 900$ million cost of the railway, to establish an 8000 t/d operation with a 16-year life. At a 2011 exchange rate of approximately R7 per US dollar, the capital cost to develop the Big Daddy chromite deposit amounts to approximately R5.5 billion. The Big Daddy project's undiscounted gross revenue was appraised at approximately $\$ 12.6$ billion. The after-tax evaluation estimated the NPV to be approximately $\$ 1.6$ billion at an $8 \%$ discount rate, or approximately $\$ 1.25$ billion at a $10 \%$ discount rate. The after-tax internal rate of return calculated to approximately $31.8 \%$, resulting in a pretax payback period of 2.5 years (CMJ, 2011; KWG Resources, 2011).

Although the NPV and IRR look promising, it is necessary to keep in mind that this investigation is conceptual in nature and that there is an inherent uncertainty surrounding some model input parameters. Intrinsically, sensitivity analysis allowed for a more in-depth investigation of the influences of some uncertainties on the overall project appraisal, which are discussed in the following sections.

\section{Cost sensitivity of the pre-oxidation process in isolation}

The overall sensitivity of the pre-oxidized chromite production cost parameters for the pre-oxidation process, consisting of a spider plot showing parameter sensitivity and a table ranking these parameters from most to least sensitive, is presented in Figure 5. The spider plot offers a comparative representation of the sensitivity of the pre-oxidized chromite production cost model elements. Input elements with the sharpest gradients represent the parameters with the greatest impact per unit of change from the base case, as denoted by the $\mathrm{x}$-axis with the base case value set at zero.

The most sensitive parameter defined through sensitivity analysis, if the pre-oxidized chromite process production cost was considered in isolation, was chromite ore cost. This is easily explained since (i) the pre-oxidation process section was considered as a separate economic component in the financial cost model to determine the oxidized chromite production cost and selling price, and (ii) approximately $90.5 \%$ of the total pre-oxidized chromite production cost is allocated to the cost of obtaining chromite ore. PF cost and PF composition were jointly the second most sensitive parameters. The cost of PF accounts for approximately 7.3\% of the total pre-oxidized chromite production cost. The percentage change from the base case for the PF composition in Figure 5 is only indicated as a negative change, which can be attributed to the kiln being operated only on PF in the base case scenario. The cost contribution of the PF to the total chromite pre-oxidizing production cost can, however, be significantly reduced if a mixture of PF and CO off-gas, or exclusively CO from the closed SAF, can be used. The use of $\mathrm{CO}$ off-gas in the prereduction kiln is not completely effective, since temperatures higher than $1250^{\circ} \mathrm{C}$ are required. Although the adiabatic flame temperature of $\mathrm{CO}$ gas is high enough (du Preez et al., 2015; Niemelä et al., 2004), it has been found in practice that PF fuel has a deeper penetrating flame. Prereduction kilns are also long (60-80 m) to ensure the required retention time of approximately 3 hours for effective prereduction. Consequently, the fuel utilized needs to be able to penetrate deep into the kiln for effective heat transfer and to maximize the area with a temperature higher than $1250^{\circ} \mathrm{C}$. It will, however, be possible to use CO off-gas in the chromite pre-oxidation process since a lower temperature $\left(1000^{\circ} \mathrm{C}\right)$ and shorter retention time (1 hour) are required, which implies a shorter kiln. The remaining preoxidized chromite production cost parameters account for less than $2.2 \%$ of the total production cost, and therefore, in terms of sensitivity, these parameters had minimal impact.

The prereduction level was also considered since it has an impact on the pre-oxidized chromite required for the prereduction process. If the prereduction level decreases from the base case, the FeCr production capacity also decreases, resulting in a decrease in the pre-oxidized chromite requirement. This will result in an increase in the production cost per ton of pre-oxidized chromite. The opposite would occur if the prereduction level increases. However, the sensitivity to the prereduction level was minimal, since it is approximately a 130 times less sensitive than chromite cost.

\section{Cost sensitivity of the pre-oxidation process integrated} with the pelletied prereduction process

Spider plot diagrams showing parameter sensitivity relating to the NPV and IRR, with a tabular ranking of these

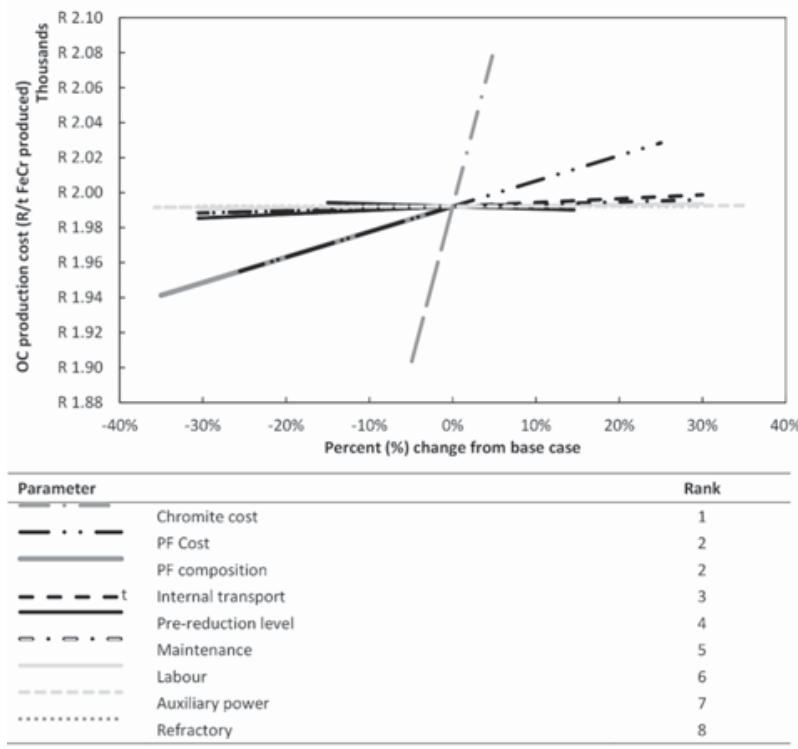

Figure 5-Overall sensitivity of pre-oxidized chromite production cost parameters 


\section{Techno-economic feasibility of a pre-oxidation process to enhance prereduction}

parameters from most to least sensitive, are presented in Figure 6 in order to illustrate the overall sensitivity of the DCF model designed for the integrated pre-oxidation and prereduction process.

Although the level of prereduction was relatively insensitive with regard to the pre-oxidation process production cost, it was found to be the most sensitive parameter in determining both the NPV and IRR. The level of prereduction, accounting for approximately $34.9 \%$ of the overall DCF sensitivity, is approximately two times more sensitive than the parameter ranked second for both the NPV and IRR. The level of prereduction primarily affects the $\mathrm{FeCr}$ production capacity, which in turn has an effect on the preoxidized chromite requirement. As a result, the level of prereduction has an effect on the chromite pre-oxidation process revenue streams (Figure 4) and consequently on the operation's cash flow. Chromite cost, the second most sensitive parameter, accounted for approximately $18.3 \%$ of the overall DCF sensitivity. Four parameters - the benefit escalation factor, $\mathrm{Cr}$ content of $\mathrm{FeCr}$, FeCr price, and cost escalation factor - could be grouped together for each, accounting for between approximately $9 \%$ and $12 \%$ of the overall DCF sensitivity. An interesting observation is that the order of importance for these four parameters was dissimilar for the NPV and IRR. Nevertheless, these cost or price parameters have significant implications for overall project feasibility by directly controlling the total available revenue from the two income streams. Specifically, significant increases in the cost of chromite and factors that adversely influence the $\mathrm{FeCr}$ price and income from FeCr sales will imply an inadequate source of revenue in order to offset the
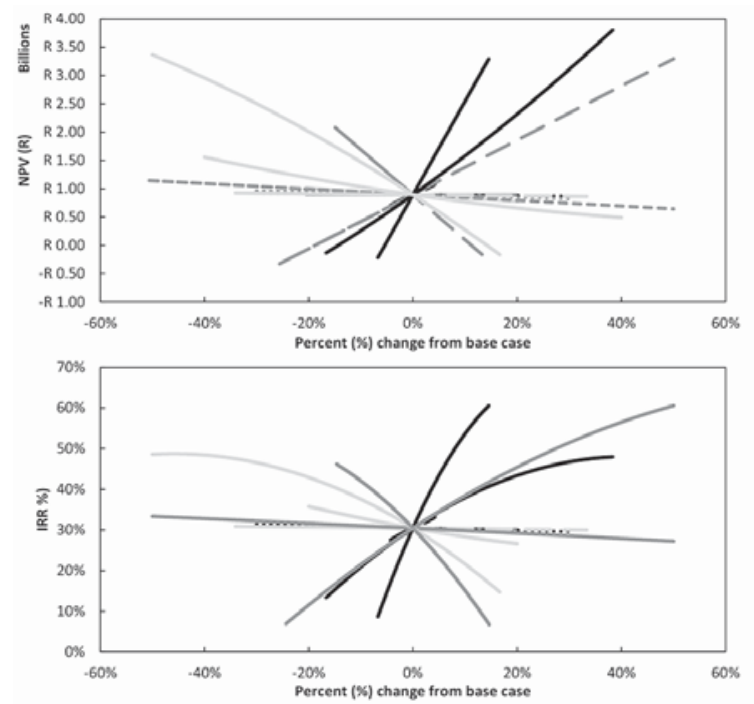

\begin{tabular}{|c|c|c|c|c|}
\hline \multirow{2}{*}{ Parameter } & & \multicolumn{2}{|c|}{ Rank } & \multirow{2}{*}{ Overall DCF sensitivity (\%) } \\
\hline & & NPV & IRR & \\
\hline - & Pre-reduction level & 1 & 1 & 34.86 \\
\hline--- & Chromite cost & 2 & 2 & 18.33 \\
\hline ------- & Benefit escalation factor & 3 & 5 & 11.90 \\
\hline$\Longleftarrow \Longleftarrow$ & Fecr Cr content & 6 & 3 & 10.26 \\
\hline--- & FeCr price & 5 & 4 & 10.21 \\
\hline & Cost escalation factor & 4 & 6 & 8.90 \\
\hline 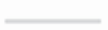 & Total capital cost & 8 & 7 & 2.33 \\
\hline ------- & Discount rate & 7 & & 1.35 \\
\hline ------- & Income tax rate & 9 & 8 & 0.97 \\
\hline .................. & Project contingencies & 12 & 9 & 0.31 \\
\hline ................. & Decommissioning cost & 10 & . & 0.23 \\
\hline & Freight cost & 11 & 11 & 0.20 \\
\hline$\longrightarrow$ & Development cost & 13 & 10 & 0.14 \\
\hline
\end{tabular}

Figure 6-Overall sensitivity of the DCF model associated costs. It is interesting to note that the total capital cost is the seventh most sensitive parameter for the IRR and the eighth most sensitive for NPV. It was originally assumed that the capital cost would have a bigger influence on project appraisal as a result of the front-loaded nature of the cash flows. However, it does not have a considerable impact on project valuation. The capital cost necessary for funding may have a more dramatic impact on the ability to secure project financing, either through debt or equity. Although this does not necessarily affect project valuation, it may have an impact on project feasibility in determining the ability to generate funding for construction. Factors of less significant influence include the discount rate, income tax rate, project contingencies, decommissioning cost, as well as freight and development costs. The significance and contribution of each of the individual parameters investigated through this research cannot be ignored. However, their ranking in terms of sensitivity has provided a means by which further research can be prioritized, and efforts can be focused on parameters that will result in the greatest influence on project valuation.

\section{Conclusions}

It was recently proven that pre-oxidation of fine chromite ore, prior to pelletized prereduction, significantly decreases the SEC and lumpy carbonaceous reductants required for furnace smelting. In this paper, we presented an analysis of the techno-economic feasibility of integrating chromite preoxidation into the currently applied pelletized prereduction process as a pretreatment method. South Africa's FeCr industry provided the ideal backdrop conditions against which the techno- economic feasibility of implementing such a process could be evaluated. Through the conceptualization of the pre-oxidation process route, it became evident that FeCr producers currently utilizing the prereduction process would most likely opt to employ an operation with a rotary kiln at its core to conduct chromite pre-oxidation. Chromite pre-oxidation at the optimum temperature of $1000^{\circ} \mathrm{C}$ translated to an increase in the level of achievable chromite prereduction of approximately $8.5 \%$ (from $46.5 \%$ to $55.5 \%$ ), approximately $8.3 \%$ improvement in the SEC (from 2.4 to $2.2 \mathrm{MWh} / \mathrm{t}$ ), and a decrease of approximately $14 \%$ (from $99.5 \%$ to $85.5 \mathrm{~kg} / \mathrm{t}$ pellets) in the amount of lumpy carbonaceous material required during SAF smelting. In order to more accurately approximate input costs for further lifecycle financial modelling, a comprehensive estimate of the costs associated with pre-oxidizing the fine chromite ore was determined. The life-cycle financial model, which was built on a DCF approach, generated a base case NPV of approximately R895 million and an IRR of approximately $30.5 \%$ after tax. This strongly indicates that integration of the chromite pre-oxidation process into the currently applied prereduction process may be viable from a financial perspective. Sensitivity analysis of the pre-oxidation process in isolation indicated that the most influential parameter was chromite ore cost, whereas if the pre-oxidation process was integrated with the pelletized prereduction process, the most influential parameter was found to be the level of prereduction. The level of achievable prereduction is interrelated with the pre-oxidation temperature, which implies that the capability of maintaining the optimum preoxidation temperature is of critical importance. 


\section{Techno-economic feasibility of a pre-oxidation process to enhance prereduction}

\section{Acknowledgements}

The authors would like to thank Glencore Alloys for technical assistance.

\section{References}

BARNES, A.R., FinN, C.W.P., and AlGIE, S.H. 1983. The prereduction and smelting of chromite concentrate of low chromium-to-iron ratio. Journal of the South African Institute of Mining and Metallurgy, vol. 83 (March) pp. $49-54$.

BASSON, J., CURR, T.R., and Gericke, W.A. 2007. South Africa's ferro alloys industry - present status and future outlook. Proceedings of the 11th International Ferro Alloys Conference (INFACON XI). Das, R.K. and Sundaresan, T.S. (eds). Indian Ferro Alloys Producers Association, New Delhi. pp. 3-24.

BeuKes, J.P., vAn ZyL, P.G., and NeIZEL, B.W. 2015. Process for enhanced prereduction of chromite. PCT/IB2013/056313. North-West University.

BEUKES, J.P., van ZYL, P.G., and RAS, M. 2012. Treatment of $\mathrm{Cr}(\mathrm{VI})$-containing wastes in the South African ferrochrome industry - a review of currently applied methods. Journal of the Southern African Institute of Mining and Metallurgy, vol. 112, no. 5. pp. 347-352.

BEuKES, J.P., DAWSON, N.F., and vAN ZyL, P.G. 2010. Theoretical and practical aspects of $\mathrm{Cr}(\mathrm{VI})$ in the South African ferrochrome industry. Journal of the Southern African Institute of Mining and Metallurgy, vol. 110, no. 12 pp. 743-750.

Biermann, W., Cromarty, R.D., and Dawson, N.F. 2012. Economic modelling of a ferrochrome furnace. Journal of the Southern African Institute of Mining and Metallurgy, vol. 112, no. 4. pp. 301-308.

ВотнA, W. 2003. Ferrochrome production through the SRC process at Xstrata, Lydenburg Works. Journal of the South African Institute of Mining and Metallurgy, vol. 103, no. 6. pp. 373-389.

Cartman, A. 2008. An analysis of ferrochrome input costs. Proceedings of the Metal Bulletin Special and Stainless Steel Summit. http://hatch.ca/Mining_Metals/Iron_Steel/Articles/documents/analysis_fer rochrome input costs.pdf [accessed 30 Jan. 2015]

CMJ. 2011. Chromite study: Big Daddy headed for feasibility. http://www.canadianminingjournal.com/news/chromite-study-big-daddyheaded-for-feasibility/ [accessed 22 Nov. 2015]

CRAMER, L.A., BASSON, J., and NELSON, L.R. 2004. The impact of platinum production from UG2 ore on ferrochrome production in South Africa. Journal of the South African Institute of Mining and Metallurgy, vol. 104, no. 9. pp. 517-527.

CREAMER, M. 2013. South Africa's raw chrome exports soar as ferrochrome edge is lost. Mining Weekly. http://www.miningweekly.com/article/southafricas-raw-chrome-exports-soar-as-ferrochrome-edge-is-lost-2013-0920 [accessed 15 Jan. 2014]

DAavitTILA, J., HonKANIEMI, M., and Jokinen, P. 2004. The transformation of ferrochromium smelting technologies during the last decades. Journal of the South African Institute of Mining and Metallurgy, vol. 104, no. 10. pp. 541-549.

Denton, G.M., BenniE, J.P.W., and DE Jong, A. 2004. An improved DC-arc process for chromite smelting. Proceedings of the 10th International Ferroalloys Congress (INFACON X). South African Institute of Mining and Metallurgy, Johannesburg. pp. 60-67.

Du PreEZ, S.P., BEUKES, J.P., and VAN ZyL, P.G. 2015. Cr(VI) generation during flaring of CO-rich off-gas from closed ferrochromium submerged arc furnaces. Metallurgical and Materials Transactions B, vol. 46B (April). pp. 1002-1010. DOI: 10.1007/s11663-014-0244-3

Dwarapudi, S., TathavadKar, V., Rao, B.C., Kumar, T.K.S., GHosh, T.K., and DENYS, M. 2013. Development of cold bonded chromite pellets for ferrochrome production in submerged arc furnace. ISIJ International, vol. 53, no. 1. pp. 9-17. DOI: 10.2355/isijinternational.53.9

Езком. 2012. Eskom retail tariff adjustment for 2012/2013. http://www.eskom.co.za/c/article/816/home/ [accessed 7 Oct. 2012]

GLASTONBURY, R.I., BEUKES, J.P., van ZyL, P.G., SADIKI, L.N., JORDAAN, A., CAmpBelL, Q.P., Stewart, H.M., and Dawson, N.F. 2015. Comparison of physical properties of oxidative sintered pellets produced with UG2 or metallurgical grade South African chromite: a case study. Journal of the Southern African Institute of Mining and Metallurgy, vol. 115, no. 8. pp. 699-706. DOI: 10.17159/2411-9717/2015/v115n8a6

Glastonbury, R.I., van DeR MERWE, W., Beukes, J.P., van Zyl, P.G., Lachmann, G., SteEnKAMP, C.J.H., DAWSON, N.F., and STEWART, H.M. 2010. Cr(VI) generation during sample preparation of solid samples - A chromite ore case study. Water SA, vol. 36, no. 1. pp. 105-110. DOI: 10.4314 /wsa.v36i1.50913

GoEL, R.P. 1997. Smelting technologies for ferrochromium production - recent trends. Ferro Alloy Industries in the Liberalised Economy. Vaish, A.K. Singh, S.D., Goswami, N.G., and Ramachandrarao, P. (eds). National Metallurgical Laboratory (NML), Jamshedpur, India.

HenRico, M. 2014. RE: De Oude Werf. Personal Communication, 25 September 2014. Glencore Alloys, Middelburg, Mpumalanga, South Africa.

Hiтch, M. and DiPple, G.M. 2012. Economic feasibility and sensitivity analysis of integrating industrial-scale mineral carbonation into mining operations. Minerals Engineering, vol. 39. pp. 268-275. DOI: 10.1016/j.mineng.2012.07.007

HolapPa, L. 2010. Towards sustainability in ferroalloys production. Proceedings of the 12th International Ferroalloys Congress (INFACON XII), Helsinki, Finland. Vartiainen, A. (ed.). Outotec Oyj. pp. 1-10.
ICDA. 2013a. Energy update - November 2013. International Chromium Development Association, Paris, France.

http://dev.icdacr.com/index.php?option=com_content\&view=article\&id=61 $7 \&$ Itemid=590\&lang=en [accessed 14 Sept. 2015]

ICDA. 2013b. Statistical Bulletin 2013. International Chromium Development Association, Paris, France.

Jones, R.T. 2015. Pyrometallurgy in Southern Africa - list of Southern African smelters. http://www.pyrometallurgy.co.za/PyroSA/index.htm [accessed 14 Sept. 2015]

Kapure, G., Tathavadkar, V., Rao, C.B., Rao, S.M., and Raju, K.S. 2010. Coal based direct reduction of preoxidized chromite ore at high temperature. Proceedings of the 12th International Ferroalloys Congress (INFACON XII), Helsinki, Finland. Vartiainen, A. (ed). Outotec Oyj. pp. 293-301.

Kleynhans, E.L.J., Beukes, J.P., van Zyl, P.G., Kestens, P.H.I., and LANGa, J.M 2012. Unique challenges of clay binders in a pelletised chromite prereduction process. Minerals Engineering, vol. 34. pp. 55-62. DOI: 10.1016/j.mineng.2012.03.021

Kleynhans, E.L.J., Neizel, B.W., BeUKES, J.P., and van ZyL, P.G. 2016. Utilisation of pre-oxidised ore in the pelletised chromite pre-reduction process. Minerals Engineering, vol. 92. pp. 114-124. DOI: 10.1016/j.Mineng.2016.03.005

KWG Resources. 2011. Daddy chromite deposits. http://www.kwgresources.com/_resources/corp_presentations/corporate_p resentation.pdf [accessed 22 Nov. 2015].

Luckos, A., Denton, G. and Den Hoed, P. 2007. Current and potential applications of fluid-bed technology in the ferroalloy industry. Proceedings of the 11th International Ferroalloys Congress (INFACON XI). Das, R.K. and Sundaresan, T.S. (eds). Indian Ferro Alloys Producers Association, New Delhi. pp. 123-132.

McCullough, S., Hockaday, S., Johnson, C. and Barcza, N.A. 2010. Pre-reduction and smelting characteristics of Kazakhstan ore samples. Proceedings of the 12th International Ferroalloys Congress (INFACON XII), Helsinki, Finland. Vartiainen, A. (ed.). Outotec Oyj. pp. 249-262.

MERAFE RESOURCES. 2014. Third quarter 2014 ferrochrome price announcement. http://www.overend.co.za/download/third_quarter_2014_30072014.pdf [accessed 3 Mar 2016].

MERAFE RESOURCES. 2012. Maximising South Africa's chrome ore endowment to create jobs and drive sustainable growth. http://www.meraferesources.co.za/pdf/presentations/2012/chrome_ore_b ochure.pdf [accessed 14 Jan. 2014].

MoHALE, G.T.M. 2014. SEM image processing as an alternative method to determine chromite pre-reduction. MSc (Chemical Engineering) dissertation, North-West University, South Africa.

MURTHY, Y.R., TRIPATHY, S.K., and KumAR, C.R. 2011. Chrome ore beneficiation challenges \& opportunities - A review. Minerals Engineering, vol. 24, no. 5. pp. 375-380. DOI: 10.1016/j.mineng.2010.12.001

NAIKER, O. 2007. The development and advantages of Xstrata's Premus Process. Proceedings of the 11th International Ferroalloys Congress (INFACON XI). New Delhi, India. Das, R.K. and Sundaresan, T.S. (eds) Indian Ferro Alloys Producers Association. pp. 112-119.

NAIKER, O. and RlLEY, T. 2006. Xstrata alloys in the profile. Proceedings of South African Pyrometallurgy 2006. Southern African Institute of Mining and Metallurgy, Johannesburg. pp. 297-306.

Neizel, B.W., BeuKes, J.P., van Zyl, P.G., and Dawson, N.F. 2013. Why is $\mathrm{CaCO}_{3}$ not used as an additive in the pelletised chromite pre-reduction process? Minerals Engineering, vol. 45. pp. 115-120. DOI: $10.1016 /$ j.mineng.2013.02.015

NiAYESH, M.J. and FlETCHER, G.W. 1986. An assessment of smelting reduction processes in the production of $\mathrm{Fe}-\mathrm{Cr}-\mathrm{C}$ alloys. Proceedings of the 4th International Ferroalloys Congress (INFACON IV), Sao Paulo, Brazil. pp. 115-123.

Niemelä, P., Krogerus, H., and OiKarinen, P. 2004. Formation, characterisation and utilisation of $\mathrm{CO}$-gas formed in ferrochrome smelting. Proceedings of the 10th International Ferroalloys Congress (INFACON X). South African Institute of Mining and Metallurgy, Johannesburg. pp. 68-77.

OCC. 2014. Beneath the surface - uncovering the economic potential of Ontario's Ring of Fire. Ontario Chamber of Commerce, Ontario, Canada.

PAN, X. 2013. Effect of South Africa chrome ores on ferrochrome production. Proceedings of the International Conference on Mining, Mineral Processing and Metallurgical Engineering (ICMMME'2013) Johannesburg, South Africa, 5-16 April 2013.

PŠUnDER, I. 2012. Use of discounted cash flow methods for evaluation of engineering projects. Mechanical Engineering. Gokcek, M. (ed.). InTech, Rijeka, Croatia.

PŠunder, I. and FERLAN, N. 2007. Analysis of the knowledge and the use of investment project evaluation methods in the field of mechanical engineering. Journal of Mechanical Engineering, vol. 53, no. 9 pp. 569-581.

SLATTER, D.D. 1995. Technological trends in chromium unit production and supply. Proceedings of the 7th International Ferroalloys Congress (INFACON VII), Trondheim, Norway. Tveit, H., Tuset, J.K., and Page, I.G. (eds). Norwegian Ferroalloy Producers Research Organization (FFF). pp. 249-262.

UGwUEGBu, C. 2012. Technology innovations in the smelting of chromite ore Innovative Systems Design and Engineering, vol. 3, no. 12. pp. 48-55.

Wellmer, F.-W., Dalheimer, M., and Wagner, M. 2008. Calculation of Cost Data. Economic Evaluations in Exploration. Springer, Berlin/Heidelberg. p. 249. 